Семенов А.А., Яицкий А.С.

ческого образования // Биоразнообразие и антропо- А.И. Золотухина / под ред. А.Н. Володченко. Сарагенная трансформация природных экосистем: мате- тов: Издательство «Саратовский источник», 2016. риалы всерос. науч.-практ. конф., посв. памяти

\title{
PREPARATION OF FUTURE BIOLOGY TEACHERS TO THEIR EDUCATIONAL UPBRINGING FUNCTIONS
}

(C) 2017

Semenov Alexander Alexeevich, candidate of biological sciences, associate professor, head of Chair of Biology, Ecology and Methods of Teaching

Yaitsky Andrey Stepanovich, senior lecturer of Chair of Biology, Ecology and Methods of Teaching Samara State University of Social Sciences and Education (Samara, Russian Federation)

\footnotetext{
Abstract. An upbringing of the younger generation is an important task of modern education. Faculty of Natural Sciences and Geography of Samara State University of Social Sciences and Education has shaped a system of training of future biology teachers to prepare them for implementation of upbringing functions. The developed system includes psychological, pedagogical and methodological disciplines, on-the-job practices and research work, as well as final State attestation. All components of the system are interrelated; they influence and complement each other. Within a framework of disciplines of «Theory and Technology of Education» and «Pedagogical Psychology», future teachers are learning the essence of upbringing, its purpose and tasks, subject matter, principles, patterns, directions, methods, technologies and evaluation criteria. While studying the «Methodology of biology teaching» discipline students get acquainted with a system of upbringing education and master methodical approaches to the formation of various elements of bringing up: formation of ideology and patriotic education, morals and aesthetics, ecology and hygiene, labor and sex educations, etc. Magistracy course of «Methodology of biology teaching» is supplemented by optional «Upbringing and socialization of students in process of biology learning». The latter is designed to prepare students to yield upbringing and socialization of students by means of biology education. Future teachers are gaining practical skills on acquired knowledge during the periods of on-the-job practices, research work and final State attestation.

Keywords: education; upbringing; learning; higher education; professional education; pedagogical education; future biology teachers; students; student-biologist; bachelor; master's degree; pedagogue; biology teacher; pedagogue functions; educational upbringing functions; socialization.
}

\section{ФОРМИРОВАНИЕ ОБЩЕКУЛЬТУРНЫХ КОМПЕТЕНЦИЙ У БУДУЩИХ ТРЕНЕРОВ - ПРЕПОДАВАТЕЛЕЙ ФИЗИЧЕСКОЙ КУЛЬТУРЫ: СОСТОЯНИЕ, ПРОБЛЕМЫ, ПЕРСПЕКТИВЫ} (C) 2017

\author{
Серпер Сергей Александрович, кандидат экономических наук, докторант СГСПУ \\ Самарский государственный социально-педагогический университет (г. Самара, Российская Федерация)
}

\begin{abstract}
Аннотация. В статье рассматривается специфика формирования общекультурных компетенций студентов профиля «Физическая культура и спорт». Федеральный государственный образовательный стандарт третьего поколения, утверждённый Министерством образования и науки Российской Федерации, предполагает формирование у студентов направления «Физическая культура и спорт» общекультурных компетенций, важных при реализации программы развития личности современного специалиста и тренера. Значение общекультурных компетенций в системе современного образования увеличивается и в связи с установлением личностноориентированной парадигмы образования, при которой социуму требуются самостоятельные, активные, способные к саморазвитию и самообразованию профессионалы, особенно в областях, жизненно важных для развития российского общества и государства. В статье показано, что развитие фитнеса сформировало такой вопрос, как педагогика фитнеса: необходимо определить не только набор профессиональных и общекультурных компетенций, содержание и структуру учебных планов для будущих профессионалов в сфере фитне$\mathrm{ca}$, но и то, какие общекультурные компетенции и каким образом способствуют формированию будущих специалистов по фитнесу, как взаимодействуют профессиональные и общекультурные компетенции в ходе учебного процесса. Решение этого вопроса позволит наиболее оптимально и эффективно реформировать систему подготовки специалистов по физической культуре и поможет реализовать государственные задачи по сохранению здоровья нации.
\end{abstract}

Ключевые слова: общекультурные компетенции; компетенции; компетентностный подход; высшее образование; физическая культура и спорт; педагогическое образование; тренер; преподаватель физической культуры; физкультурно-спортивное образование.

В современной педагогической науке существует большой комплекс исследований, где затрагиваются как общие вопросы формирования общекультурных компетенций, так и конкретные проблемы подготовки будущих специалистов по физической культуре. Для понимания современного состояния теоретико- методологической основы и подходов к процессу формирования общекультурных компетенций необходимо рассмотреть оба комплекса трудов, указанные выше.

Прежде всего, необходимо отметить, что на настоящий момент нет всестороннего диссертацион- 
ного исследования, в котором бы рассматривалась данная проблема. Тем не менее существуют диссертации, где анализируются либо смежные вопросы, либо некоторые аспекты предмета нашего исследования.

Так, процесс формирования профессиональных (но не общекультурных) компетенций специалистов (как будущих, так и действующих) по физической культуре и спорту изучается в трудах Л.М. Певицыной [1], А.Ю. Середы [2], С.Н. Кривсун [3], Н.В. Никифорова [4], С.В. Шенделевой [5], Б. Бямбаринчин [6], Е.Н. Григорьева [7], В.Ф. Пешкова [8]. Количество диссертационных исследований свидетельствует о востребованности и актуальности поиска решения и ответа на вопрос, каким образом наиболее оптимально сформировать профессиональные компетенции будущих специалистов по физической культуре и спорту в различных условиях. Однако при многоступенчатой системе высшего образования и реализации ФГОС 3+ игнорирование исследователями проблемы формирования общекультурной компетенции может привести к весьма негативным последствиям как для студентов, так и для всей системы образования в целом.

Данные тенденции уже прослеживаются в выводах в приведённых диссертационных исследованиях. Большой заслугой отечественных учёных можно назвать выработку нескольких подходов к определению понятия «профессиональная компетенция бакалавра физической культуры». Если обобщить данные подходы, то под профессиональными компетенциями понимается система сформированных способностей, знаний и умений в следующих областях профессиональной деятельности: педагогическая, проектная, исследовательская, культурно-просветительская [9; 10, с. 4-9; 11, с. 21-23].

Исследователи солидарны в том, что освоение профессиональных компетенций предоставит будущим специалистам не только возможность вести педагогическую работу в школе по предмету «Физическая культура», но участвовать в организации соревнований, даст базовые элементы тренерской и судейской подготовки, позволит вести научно-исследовательскую работу [12, с. 104-107].

В целом в настоящее время хорошо изучены многие аспекты формирования профессиональных компетенций будущих специалистов по физической культуре и спорту, за исключением одной важной темы: взаимосвязи процесса формирования профессиональных и общекультурных компетенций, хотя сам текст федерального образовательного стандарта предполагает акцент именно на такой связи, а её надлежащего теоретико-методологического обоснования в современных исследовательских работах очень мало.

С другой стороны, существует достаточно значительный комплекс трудов, изучающих процесс формирования какой-либо одной общекультурной компетенции бакалавров профиля «Физическая культура и спорт». Так, в исследованиях К.А. Маринченко рассматриваются особенности совершенствования личностных качеств студентов, поддержания их стремления к саморазвитию в области личностного роста и коммуникации, а также ставится задача: «Привить навыки использования своих учебных умений, межличностного общения и психофизиологического состояния; сформировать у студентов убеждение в необходимости совершенствования качества знаний для успешной профессиональной деятельности» [13, с. 256]. Видно, что обозначенные положения соответствуют формулировке общекультурной компетенции (ОК-6) федерального стандарта: «Способность к самоорганизации и самообразованию».

В этом же ключе выполнены исследования А.А. Оплетина и В.Д. Паначева, где сделан вывод, что разработанная учёными система педагогического аутотренинга содействует более эффективной саморегуляции и самоуправлению, повышая тем самым жизненный тонус, улучшая психическое и физическое здоровье. В статье особо отмечается: «В процессе занятий педагогическим аутотренингом на занятиях физической культурой создаются психологические установки на формирование компетенции саморазвития, что способствует формированию профессиональной направленности личности студента» [14, с. 133-140]. Однако указанные положительные эффекты авторы относят к сфере профессиональных компетенций, тогда как, по федеральному стандарту, отмеченные формируемые способности и знания лежат в области общекультурных компетенций (ОК-6).

В статье Е.К. Старикова и Е.Л. Месенина рассмотрен другой аспект данной проблемы - формирование системы усвоения набора компетенций и знаний по безопасному поведению в спорте, а также формирование культуры сохранения здоровья и жизни субъектов и объектов спорта [15, с. 207-209]. И, хотя в статье это дополнительно не обозначено, можно заметить, что речь идёт об изучении процесса формирования общекультурной компетенции (ОК-9), нацеленной на формирование способности оказания первой помощи и физической безопасности.

О безопасности (только безопасности информационной) как элементе общекультурных компетенций у будущих педагогов по физической культуре пишут в своей работе Ю.И. Богатырева, А.Н. Привалов, В.А. Романов [16, с. 99]. При таком подходе, согласно федеральному государственному стандарту, формируется общекультурная компетенция (ОК-3): «Способность использовать естественнонаучные и математические знания для ориентирования в современном информационном пространстве».

Э.В. Маркин и Ю.А. Читаева рассматривают особенности развития коммуникативной компетенции будущих специалистов по физической культуре и спорту $[17$, с. 219-223; 18, с. 406-409]. Одну из немногочисленных попыток изучить процесс формирования общекультурных компетенций у студентов направления «Физическая культура и спорт» в комплексе, а не на примере одной компетенции, предприняли Г.Л. Драндров и И.Ф. Файзуллин [19]. Однако их исследование направлено на решение достаточно узкой задачи в плане формирования компетенций - проследить, как данный процесс происходит в условиях волонтёрской деятельности студентов на крупных спортивных мероприятиях. Вывод авторов: «Подготовка и участие студентов в волонтёрской деятельности на крупных спортивных мероприятиях на основе реализации разработанной нами теоретической модели и комплекса педагогических 
условий приводят к существенному повышению показателей свойств личности, обусловливающих проявление общекультурных компетенций: социальной креативности, вербальной самооценки, волевого потенциала, творческого потенциала, адаптации, принятия других, внутреннего контроля и стремления к доминированию» [19, с. 396].

Указанные компетенции охватывают далеко не весь комплекс общекультурных компетенций, отмеченных в федеральном стандарте. Следовательно, проблема содержания теоретико-методологической основы для формирования общекультурных компетенций у студентов направления «Физическая культура и спорт» ещё не нашла должного отражения в научной литературе.

В целом исследователи, рассматривающие особенности формирования какой-либо конкретной общекультурной компетенции у будущих специалистов по физической культуре и спорту, сходятся во мнении, что для качественной реализации компетентностного подхода в вузе необходимо создание особых педагогических условий, при которых процесс формирования выделенной общекультурной компетенции пойдет наиболее плодотворно, эффективно и оперативно. К таковым условиям, как правило, относят изменение структуры и содержания педагогического процесса в вузе, совершенствование методов и форм обучения, сочетание как аудиторной, так и самостоятельной работы студентов.

Вопрос об углублении и развитии содержания физкультурного образования в свете формирования общекультурных компетенций возможно решить за счёт введения таких дисциплин, как «Основа фитнеса», «Организация фитнеса», «Управленческие основы работы фитнес-тренера» и др. За счёт данных дисциплин и факультативных занятий представляется, что процесс формирования общекультурных компетенций пойдёт более эффективно, охватывая больший набор компетенций, что совершенно необходимо для современного образования и общества.

И в этом плане процесс формирования общекультурных компетенций должен иметь перед собой цель не только подготовить выпускников к участию в профессиональной (тренерской, спортивной и педагогической) деятельности, но и, как этого требует федеральный стандарт, к проектной, исследовательской, культурно-просветительской деятельности; учитывая, что речь идёт о физкультурно-спортивном образовании, то и к эффективной реализации программных установок федеральных целевых программ [20], таких, например, как «Стратегия развития физической культуры и спорта в Российской Федерации на период до 2020 года».

\section{СПИСОК ЛИТЕРАТУРЫ:}

1. Певицына Л.М. Научно-методические аспекты совершенствования профессиональной компетентности учителей физической культуры в процессе повышения квалификации: автореф. дис. ... канд. пед. наук. Ростов-на-Дону, 2007. 23 с.

2. Середа А.Ю. Формирование ключевых компетентностей у спортивного менеджера в условиях социально-экономической трансформации: автореф. дис. ... канд. пед. наук. СПб., 2011. 26 с.

3. Кривсун С.Н. Формирование профессиональных базовых компетенций педагога физической культуры: автореф. дис. ... канд. пед. наук. Ростовна-Дону, 2011. 24 с.

4. Никифоров Н.В. Формирование профессиональной компетентности будущих педагогов-тренеров по вольной борьбе: автореф. дис. ... канд. пед. наук. Якутск, 2009. 25 с.

5. Шенделева С.В. Подготовка будущих учителей к формированию культуры здоровья школьников в педагогических вузах России: 1918 - конец 90-х гг. XX в.: автореф. дис. ... канд. пед. наук. Чита, 2008. $22 \mathrm{c}$.

6. Бямбаринчин Б. Формирование умений и навыков двуязычного профессионального общения у будущих специалистов спортивного профиля в вузе: автореф. дис. ... канд. пед. наук. Красноярск, 2013. $21 \mathrm{c}$.

7. Григорьев Е.Н. Формирование профессионально-значимых качеств личности будущих тренеровпреподавателей в компетентностно-ориентированном образовательном процессе вуза: автореф. дис. ... канд пед наук. Уфа, 2010. 23 с.

8. Пешков В.Ф. Педагогическая система профессиональной восстановительно-профилактической подготовки педагогов по физической культуре: автореф. дис. ... д-ра пед. наук. Томск, 2009. 44 с.

9. Балашова В.Ф. Компетентность специалиста по адаптивной физической культуре: монография. М., 2008. 150 с.

10. Алпеева Л.С. Профессиональные компетенции педагога высшей школы // Новое в лингвистике и преподавании иностранных языков. СПб., 2015. С. 4-9.

11. Макаренко В.Г. Конфликтологическая подготовка в системе формирования профессиональных компетенций педагога по физической культуре и спорту в вузе // Теория и практика физической культуры. 2007. № 10. С. 21-23.

12. Макаренко В.Г. Научно-исследовательская работа студентов в системе формирования профессиональных компетенций специалиста по физической культуре и спорту // Вузовское преподавание: проблемы и перспективы: мат-лы 8-й междунар. науч.практ. конф. Челябинск, 2007. С. 104-107.

13. Маринченко К.А. Пути формирования в вузе компетенции профессионально-личностного самосовершенствования у будущих преподавателей физической культуры и спорта // Учёные записки Орловского государственного университета. Серия: Гуманитарные и социальные науки. 2010. № 3-2. С. 256.

14. Оплетин А.А., Паначев В.Д. Саморазвитие личности студента средствами педагогического аутотренинга на занятиях физической культурой // Педагогико-психологические и медико-биологические проблемы физической культуры и спорта. 2015. № 2 (35). C. $133-140$.

15. Старикова Е.К., Месенина Е.Л. Системный подход к формированию культуры безопасного поведения как составляющей общекультурных компетенций в спорте // Оптимизация учебно-воспитательного процесса в образовательных учреждениях физической культуры: ХХІІІ региональная науч.-метод. конф. с междунар. уч. Челябинск: Уральский государственный университет физической культуры, 2013. C. 207-209.

16. Богатырева Ю.И., Привалов А.Н., Романов В.А. Формирование информационной безопасности у бу- 
дущих специалистов в области физической культуры и спорта // Теория и практика физической культуры. 2015. № 5. С. 99.

17. Маркин Э.В. Формирование коммуникативной компетенции будущих специалистов по физической культуре и спорту в вузе // Физическая культура, спорт и здоровье студенческой молодежи в современных условиях: сб. материалов всерос. науч.метод. конф. Орёл: Орловский государственный аграрный университет, 2013. С. 219-223.

18. Читаева Ю.А. Формирование одного из кластеров ключевых компетенций «коммуникабельность» модели ключевых компетенций тренерскопреподавательского персонала в рамках кадрового обеспечения физической культуры и спорта // Физи- ческая культура, спорт и здоровье в современном обществе: сб. науч. статей всерос. с междунар. уч. науч.-практ. конф. / редколлегия: Г.В. Бугаев, О.Н. Савинкова. Воронеж, 2012. С. 406-409.

19. Драндров Г.Л., Файзуллин И.Ф. Формирование у студентов вузов физической культуры и спорта общекультурных компетенций в процессе волонтёрской деятельности на крупных спортивных мероприятиях // Современные проблемы науки и образования. 2015. № 6-0. С. 396.

20. Стратегия развития физической культуры и спорта в Российской Федерации на период до 2020 года [Электронный ресурс] // http://minsport. gov.ru/activities/federal-programs/2/26363.

\title{
DEVELOPING CULTURAL AWARENESS IN FUTURE TEACHERS OF PHYSICAL EDUCATION: CURRENT SITUATION, ISSUES, PROSPECTS
}

(C) 2017

Serper Sergey Aleksandrovich, candidate of economical sciences, doctoral candidate of SSUSSE Samara State University of Social Sciences and Education (Samara, Russian Federation)

Abstract. The paper deals with the specifics of development of common cultural competence of students majoring in physical culture and sport. Federal state educational standard of the third generation, approved by the Ministry of Education and Science of the Russian Federation, involves development of common cultural competencies that are important for the implementation of the personality program development of a modern expert and a trainer. The value of common cultural competence in the system of modern education increases because of personality-oriented education paradigm, in which the society requires active, capable of self-development and self-education professionals, especially in areas that are vital for the development of Russian society and the state. The paper shows that the development of fitness has formed such a question as fitness pedagogy: it is necessary to determine a set of professional and general cultural competence, content and curriculum framework for future professionals in the field of fitness, to find necessary common cultural competences and how they contribute to the development of the future experts in fitness, how to interact with the professional and general cultural competence in the educational process. Solving this problem will allow to reform the system of experts training in a most optimal and efficient way and will help to realize national objectives to preserve the nation's health.

Keywords: general cultural competence; competence; competence approach; higher education; physical culture and sport; teacher education; coach; physical education teacher; physical culture and sports education.

УДК 371.21

Статья поступила в редакцию 04.10.2017

\section{РОЛЬ И ЗНАЧЕНИЕ ВОЕННО-ПЕДАГОГИЧЕСКИХ ТРАДИЦИЙ НА СОВРЕМЕННОМ ЭТАПЕ РАЗВИТИЯ СИСТЕМЫ ОТЕЧЕСТВЕННОГО ВОЕННОГО ОБРАЗОВАНИЯ}

(C) 2017

\author{
Стародубцев Михаил Павлович, кандидат педагогических наук, доцент, \\ профессор кафедры теории и методики непрерывного профессионального образования \\ Санкт-Петербургский военньій институт войск национальной гвардии Российской Федерации
} (2. Санкт-Петербург, Российская Федерация)

\footnotetext{
Аннотация. В статье рассмотрены вопросы, касающиеся роли и значения военно-педагогических традиций на современном этапе развития системы отечественного военного образования. Автором исследуются определения понятий «традиции», «педагогические традиции», «воинские традиции», предлагается авторская трактовка понятия «военно-педагогические традиции». Исследование военно-педагогических традиций проводится во взаимосвязи с достижениями военно-педагогической мысли предшествующих периодов и современными проблемами военной педагогики. Анализируются причины реформирования и модернизации, проводимых в настоящее время в системе военного образования, которые вызваны необходимостью соответствия европейским стандартам качества и новым требованиям действующего российского законодательства. В условиях перехода на многоуровневую систему подготовки и реализации компетентностного подхода в обучении, к выпускникам военных образовательных организаций предъявляются высокие требования как в части их профессиональной подготовки, так и нравственного воспитания. В этой связи, по мнению автора, особое значение приобретают формы, методы и способы такой подготовки, основанные на лучших достижениях военно-педагогической мысли, как традиционных, так и дополненных инновационными компонентами. Обращая внимание на специфику и особенности военно-педагогического процесса в современном вузе, обусловленные необходимостью включения обучающихся в реальную военно-профессиональную деятельность,
} 